\title{
O ensino de conceitos computacionais para alunos do ensino médio: relato de experiência de uma gincana e das estratégias utilizadas pelos alunos na resolução das atividades desplugadas
}

\author{
Alisson Vinícius de Souza Barbosa, Augusto Felix Pereira Neto, Rháleff \\ Nascimento Rodrigues de Oliveira, Tayná Luana Silva da Costa, Ana Liz Souto \\ Oliveira De Araújo, Flávia Veloso Souza Costa
}

Centro de Ciências Aplicadas e Educação - Universidade Federal da Paraíba (UFPB) Avenida Santa Elizabete, s/n - CEP 58.297-000 - Rio Tinto - PB - Brasil

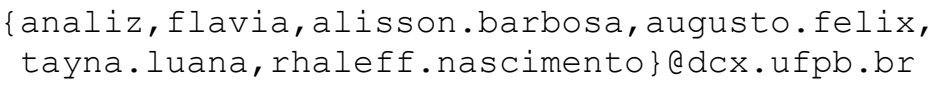

\begin{abstract}
The educational concepts of computer science in basic education has aroused discussions on the implementing methods. The unplugged computing is a method that seeks to explore concepts of computing without the use of computers. There are many reports of positive experiences on the application of this method, however, there are few studies on its assessment that seek to identify the coping strategies that students use to solve the proposed activities. This paper presents an account of experience of planning, execution and identify the strategies developed by the students to solve the questions posed unplugged computing.
\end{abstract}

Resumo. $O$ ensino de conceitos da ciência da computação na educação básica tem despertado discussões sobre os métodos de aplicação. A computação desplugada é um método que busca explorar conceitos da computação sem o uso de computadores. São muitos os relatos de experiências positivas sobre a aplicação desse método, entretanto, são poucos os estudos sobre sua avaliação que buscam identificar as estratégias de resolução que os alunos utilizam para resolver as atividades propostas. Este trabalho apresenta um relato de experiência de planejamento, execução e identificação das estratégias desenvolvidas pelos alunos para resolver questões propostas da computação desplugada.

\section{Introdução}

O ensino de computação nas escolas de ensino médio do Brasil ainda ocorre de forma bastante discreta. Ainda são poucas as escolas que oferecem em sua matriz curricular o ensino de conceitos computacionais. No Brasil, na maioria das vezes, o aprendizado de conceitos computacionais é reservado apenas aos que optam por cursos superiores ou técnicos na área [França et al, 2012]. Em algumas escolas públicas, já existem laboratórios de informática, mas em sua maioria são ministradas aulas que se referem às instruções voltadas para capacitar o manuseio de aplicativos de escritório, a edição gráfica e de ferramentas de gerenciamento de conteúdo web, como afirma [Scaico et al 2012].

O ensino de conceitos computacionais na educação básica pode desenvolver nos alunos habilidades do pensamento computacional, como por exemplo, resolução de 
problemas e raciocínio lógico [Wing, 2008]. Essas habilidades não se restringem a profissionais da área da ciência da computação, mas também no ensino de outras ciências como matemática, física, química, filosofia, sociologia dentre outras, capacitando os estudantes a sistematizar e organizar a solução de problemas [Nunes, 2011]. Uma maneira de introduzir os conceitos computacionais é por meio da computação desplugada, definida como um conjunto de atividades desenvolvidas com a finalidade de ensinar tais conceitos de forma lúdica e sem a utilização de computadores. Segundo [Scaico et al, 2012] as atividades propostas possibilitam que os alunos aprendam como o computador resolve problemas fazendo uso de uma abordagem orientada a problemas e a desafios. A computação desplugada desenvolve o raciocínio lógico dos alunos, estimula a resolução de problemas e a criatividade em um contexto significativo [Bell et al, 2011].

Este trabalho apresenta um relato de experiência do planejamento, execução, e identificação das estratégias utilizadas pelos alunos na resolução das atividades de uma gincana desplugada. O presente artigo está estruturado da seguinte forma: a seção 2 apresenta experiências de aplicação de computação desplugada no Brasil; a seção 3 apresenta o planejamento e a execução da gincana; a seção 4 mostra a análise dos resultados, bem como as estratégias de resolução identificadas durante a realização das atividades. Por fim, na seção 5, as considerações finais e trabalhos futuros.

\section{A computação desplugada como ferramenta de apoio ao ensino de conceitos computacionais}

Diversos artigos relatam experiências com o uso de atividades da computação desplugada. Em [Scaico, 2012] é relatada a experiência de estagiários com o ensino de números binários para alunos do $5^{\circ}$ ao $9^{\circ}$ ano do Ensino Fundamental. Foi percebida a necessidade de adaptações da atividade "contando os pontos" uma vez que os alunos estavam com dificuldade de abstrair o significado do 'zero' e do 'um' para o computador. A atividade, que originalmente usa cartões com pontos que representam os bits e seus valores, passou a utilizar cartões confeccionados com lâmpadas. A lâmpada acesa indica que o bit estaria ligado (sendo chamado de um) e a lâmpada apagada o bit desligado (sendo chamado de zero). Após a modificação da atividade os estagiários observaram que o desempenho dos alunos melhorou.

O trabalho de [Wilson, 2014] relata a experiência de uso de computação desplugada com crianças que apresentavam necessidades especiais. Devido os diferentes diagnósticos dos alunos, algumas atividades propostas pelo livro tiveram que ser adaptadas, mas sem perder seu foco e seu conceito. Contudo, não foram descritas tais adaptações. No final da realização das atividades foi aplicado um questionário de avaliação de resultados obtidos pelos alunos. O questionário possuía oito questões de 
múltipla escolha (Nem um pouco, Pouco, Bastante e Demais) sobre o comportamento do aluno após a realização das atividades e uma justificativa ao final do questionário.

No trabalho de [Bezerra, 2014] as atividades desplugadas foram aplicadas por alunos de Licenciatura em Ciência da Computação que estavam cursando a disciplina de "Introdução à Computação". Os alunos organizaram uma gincana que foi realizada em uma escola que funciona dentro da própria universidade. $\mathrm{Na}$ elaboração da gincana foram utilizadas as atividades propostos no livro de computação desplugada de Bell et al [2011]. Alguns materiais foram usados para dinamizar algumas atividades do livro. Por exemplo, para conhecer o número binário, um membro do grupo precisava encher um balão até que o mesmo estourasse, pois o número binário estava escrito em um papel dentro do balão. Como resultados o autor destaca a oportunidade que os alunos de computação tiveram em vivenciar experiência em sala de aula e dos alunos da escola de aprenderem conceitos de computação de forma divertida.

Também podemos encontrar na literatura relatos como o de [Silva, 2014] onde a computação desplugada é utilizada em conjunto com outras abordagens. [Silva, 2014] relata os resultados obtidos a partir da aplicação de oficinas de Scratch e Computação Desplugada a 103 professores do Curso de Aperfeiçoamento em Docência na Escola de Tempo Integral. Na oficina de desplugadas foram aplicadas duas atividades do livro "Computer Science Unplugged" [Bell et al, 2011]. Para verificar se a atividade foi bem aceita, foi monitorado o comportamento e grau de interesse dos professores. Além disso, após a oficina, um questionário foi aplicado com o objetivo de verificar a fixação dos conhecimentos e possíveis dúvidas acerca do conteúdo apresentado. Os resultados obtidos na oficina foram satisfatórias.

É possível verificar no Quadro 01 um resumo das características descritas nos trabalhos relacionados. Observamos que os trabalhos apresentados foram realizados com um público variado. Em alguns momentos foi necessária a adaptação das atividades para atender as necessidades do grupo.

Quadro 01: Resumo das características presentes nos trabalhos

\begin{tabular}{|c|c|c|c|c|c|}
\hline & Público-alvo & $\begin{array}{c}\text { Uso de } \\
\text { atividades } \\
\text { do livro }\end{array}$ & $\begin{array}{c}\text { Modificação } \\
\text { das atividades } \\
\text { do livro }\end{array}$ & $\begin{array}{l}\text { Criação de } \\
\text { novas } \\
\text { atividades }\end{array}$ & Gincana \\
\hline [Scaico, 2012] & $\begin{array}{c}\text { Ensino } \\
\text { fundamental } 2\end{array}$ & & $\mathrm{X}$ & & \\
\hline [Wilson, 2014] & $\begin{array}{c}\text { Crianças com } \\
\text { necessidades } \\
\text { especiais }\end{array}$ & & $\mathrm{X}$ & & \\
\hline [Bezerra, 2014] & $\begin{array}{c}\text { Ensino } \\
\text { fundamental e } \\
\text { médio }\end{array}$ & $X$ & & & $\mathrm{X}$ \\
\hline [Silva, 2014] & Professores & $\mathrm{X}$ & & & \\
\hline
\end{tabular}




\section{Planejamento e execução}

Esta atividade foi planejada por bolsistas do PIBID (Programa Institucional de Bolsa de Iniciação à Docência) do curso de Licenciatura em Ciência da Computação da UFPB (Universidade Federal da Paraíba) na cidade de Rio Tinto.

A equipe confeccionou e desenvolveu todos os materiais que foram utilizados durante a gincana, como planos de aula, slides e os recursos utilizados durante as atividades (incluindo as atividades complementares). A seguir são apresentados o planejamento e um relato da execução da gincana.

\subsection{O planejamento da gincana}

A gincana foi planejada para ocorrer em duas etapas, organizadas em três encontros presenciais semanais. O planejamento foi iniciado com a seleção das atividades apresentadas no livro de [Bell et al, 2011], sendo elas: Contando os Pontos; Trabalhar com Números Binários; Enviar Mensagens Secretas; Colorindo com números; Mini Fax; Crie Sua Própria Imagem; Você pode repetir?; A Mágica de virar as cartas e Árvores de Decisão.

A primeira etapa ocorreu em dois encontros. No primeiro encontro foi apresentado aos alunos os conceitos necessários para compreenderem o sistema de numeração binária. Para apresentar esses conceitos foram utilizadas cartelas (um lado na cor branca e preto de outro) com lâmpadas (acesas e apagadas) para referenciar a contagem em binário. Foi elaborada uma atividade de conversão pelos bolsistas para ajudar no entendimento dos alunos antes de serem aplicadas as atividades propostas por Bell et all [2011]. Em seguida, cada equipe recebeu um papel contendo a atividade "Trabalhar com Números Binários" [Bell et al, 2011, p. 7]. Logo após, para complementar a apresentação dos conceitos de representação de informação, foi escolhida a atividade 'Transparência: Colorindo com números' [Bell et al, 2011, p. 16].

O segundo encontro foi planejado buscando apresentar aos alunos de que maneira o computador armazena informações. Para o encontro foram selecionadas as atividades 'Você pode repetir?' [Bell et al., 2011 p. 24-25], 'A mágica de virar as cartas' [Bell et al., p. 33], e 'Vinte palpites' [Bell et al., 2011 p. 39]. As duas primeiras atividades abordam conceitos de representação da informação e a forma como é tratado a falha no armazenamento. A terceira atividade introduz formas de mensurar o conteúdo da informação.

No terceiro encontro o conceito de algoritmo foi apresentado aos alunos através de exemplos do cotidiano - como trocar uma lâmpada queimada. Nesta etapa não foi utilizada atividade do livro. Foi solicitado que cada equipe elaborasse um algoritmo para preparar um miojo.

Questionários foram aplicados visando o levantamento de dados relevantes às experiências dos alunos em participar da gincana. Após uma semana do término da gincana desplugada, uma volta a escola aconteceu para aplicação de uma atividade de revisão, contendo exercícios de conversão binária e representação apenas para checar se os alunos ainda lembravam do que haviam estudado. No mesmo dia, alguns alunos foram entrevistados e puderam dar sua opinião sobre a gincana. 


\subsection{Execuções das gincanas}

Foram realizadas duas gincanas no período de agosto à setembro de 2014. As gincanas ocorreram em escolas estaduais diferentes. Os participantes foram alunos do $1^{\circ}$ ano do ensino médio do turno da tarde de cada uma das escolas.

Primeiro foi aplicado um questionário sociocultural para conhecer o perfil de cada aluno, identificando se os mesmos já tiveram ou tem contato com o computador, assim como, quais são as disciplinas que eles mais gostavam e as que menos gostam. Para divisão das equipes, os monitores dividiram a turma em quatro grupos, cada grupo contendo em média seis alunos. Foram explicadas as regras da gincana e em seguida iniciou-se a apresentação do conteúdo de numeração binária. Alguns alunos sentiram dificuldades com o conteúdo, mas logo eles começaram a questionar sobre os conceitos e expor suas dúvidas relativas ao assunto.

Para explicar conceitos de binários, foi utilizada a metodologia de ensino "das lâmpadas" aplicado em [Scaico et al, 2012]. Após a explanação, alguns alunos continuaram com dúvidas, então, foi solicitado que alguns desses alunos fizessem uma fila de forma que quem estava virado para frente da turma representava um bit ligado, ou a lâmpada acessa e quem estivesse de costas um bit desligado, ou a lâmpada apagada - ficou acordado em acrescentar esse momento também na segunda gincana. Essa a d a p t ação ajudou aos alunos na compreensão sobre como ocorre a conversão dos números binários para decimais.

O segundo encontro foi iniciado com a realização da atividade "Você pode repetir?". Para realização da atividade foi montada u ma estrutura de frases no chão e entregue aos capitães de cada equipe letras que estavam faltando para completar cada frase. Devido ao tamanho da sala, duas equipes realizaram a atividade primeiro, enquanto as outras duas aguardavam do lado de fora - outra adaptação. Todas as equipes realizaram bem esta atividade. Em seguida, a atividade "A Mágica de virar as cartas" foi aplicada. A atividade consiste em que uma das equipes monta uma matriz quadrada $6 \times 6 \mathrm{e}$ como foi ensinado, o aluno deveria encontrar a carta de paridade em cada linha e coluna, para assim, detectar e corrigir o erro. O capitão da outra equipe era responsável em escolher e virar uma carta para que os membros da equipe adversária descobrissem qual foi a carta modificada. Por último foi aplicada a atividade "Vinte palpites". Observou-se que os alunos sentiram dificuldades para entender esta atividade, com isso, uma explicação mais detalhada foi feita. Contudo foi possível perceber que as dificuldades estavam relacionadas à conceitos matemáticos que eles não sabiam/ou lembravam.

O terceiro dia começou bastante movimentado, as equipes estavam animadas para se tornarem campeãs. A gincana começou com uma aula explicando o conceito de algoritmos, e em seguida foi passada a atividade para elaboração de um algoritmo de preparação do miojo. Depois foram aplicadas mais duas atividades com assuntos relacionados aos dias anteriores. Feito isso, a equipe campeã foi anunciada e a gincana encerrada.

\section{Análise e discussões dos resultados}

Vinte e quatro alunos participaram da primeira aplicação da gincana desplugada. Os alunos conseguiram entender os conteúdos e realizar as atividades solicitadas. Entretanto, $80 \%$ dos alunos afirmaram ter sentido dificuldades em pelo menos uma das atividades, porém no decorrer da gincana, com o apoio dos bolsistas, foi possível compreender o conteúdo e dar sequência às atividades. Na segunda aplicação da gincana desplugada 
vinte e um alunos participaram. Ao final da gincana $90 \%$ dos alunos participantes das duas gincanas demonstrou o desejo de participar de outras oficinas.

Quando foi iniciada a aula sobre algoritmos, os alunos não tinham conhecimento prévio, mas com as explicações em andamento, os mesmos começaram a perceber do que se tratava e os próprios afirmaram utilizar algoritmos em seu cotidiano. Os exemplos utilizados foram os mais simples possíveis, desde de como passar um batom na boca, até o escovar dos dentes. Foi necessário fazer com que eles entendessem que o passo a passo para quase tudo que fazemos é importante, definir uma sequência para chegar a um objetivo significa ter organização para até mesmo montar sua agenda de estudos. Tais conceitos aprendidos na gincana desplugada podem facilitar o aprendizado em disciplinas no ensino básico.

Nas duas aplicações da gincana pode-se observar que alguns alunos utilizaram estratégias que os monitores ensinaram. Uma outra parte desses alunos, assim como é mostrado nas descrições das atividades de cada escola, utilizou sua própria estratégia. Os jovens conseguiram assimilar o que foi passado e criar sua própria forma de resolução, utilizaram de artifícios, tais como, enumeração dos passos em um algoritmo, desenhar as lâmpadas para melhorar a visualização nas atividades de conversão de binários e etc. É importante que isso aconteça, pois o aluno quando estimulado de maneira correta passa a ter mais confiança no que faz e começa a pensar em diversas maneiras para resolução de vários problemas. A seção a seguir apresenta as diferentes estratégias utilizadas pelos alunos na realização das atividades.

\subsection{Estratégias utilizadas na resolução das atividades}

Na aula de binários foi aplicado uma atividade de conversão elaborada para avaliar a aprendizagem dos alunos. Durante as explicações sobre os números binários, alguns alunos foram alocados de frente para a turma - como foi explicado no tópico 3.2. Então, um número decimal imaginário foi atribuído acima da cabeça dos alunos em destaque - iniciado por 1 da direita para a esquerda (os números seguintes seriam o dobro do primeiro e assim por diante). Foi explicado que a conversão de binário para decimal é feita levando em consideração cada bit ligado/desligado. Para enfatizar ainda mais esta explicação, cartões com lâmpadas e desenhos feitos no quadro foram utilizados. Durante a realização do exercício, que pedia para que os alunos fizessem a conversão de binário para decimal e decimal para binário, notou-se que os alguns alunos utilizaram estratégias distintas.

\section{- Estratégias (parte 1 - Números binários)}

A figura 1 apresenta duas maneiras diferentes de resolução da atividade de conversão de binário para decimal. Na primeira estratégia, o aluno enumerou apenas os números que correspondem ao bit ligado (número 1). O mesmo colocou o número decimal em cima de cada bit para facilitar a soma e fazer a conversão - essa soma é feita com os números que estiverem acima dos bits ligados. Então, o aluno fez a soma dos valores relacionados aos uns e conseguiu identificar que a forma decimal do número 10101 é 21. Na estratégia 2, o aluno utilizou o conceito das lâmpadas, trocou os zeros e os uns pelo desenho das lâmpadas acessas ou apagadas. Assim como o exemplo da estratégia 1, utilizou os números decimais acima das lâmpadas. 


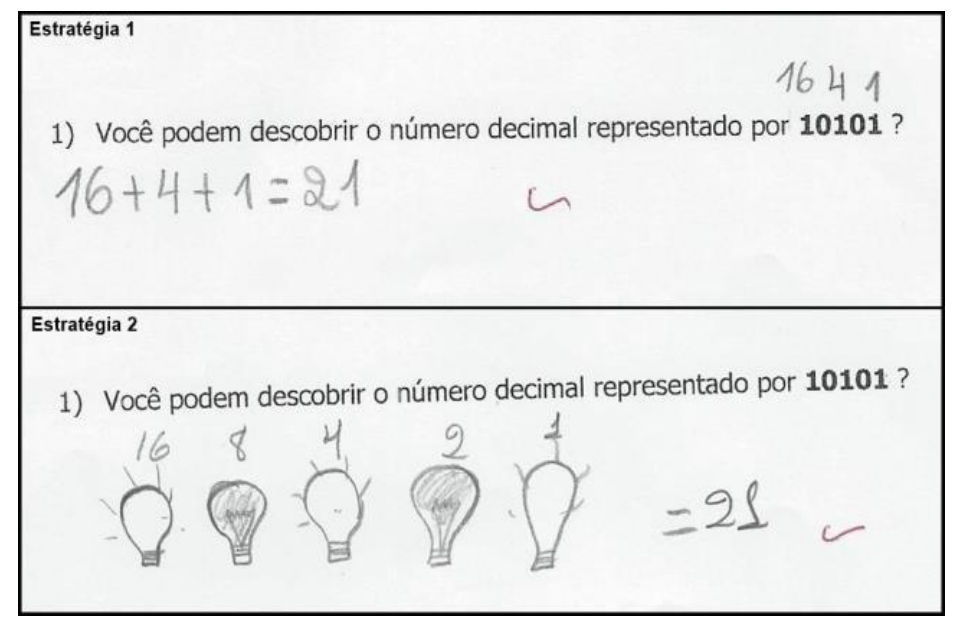

Figura 1 - Atividade de conversão de binário para decimal

Em relação a conversão de decimal para binário, também foi identificado o uso de diferentes estratégias. A Figura 2 apresenta duas estratégias. Na estratégia 1, o aluno utilizou uma forma de dedução e identificou através da soma dos valores dos bits acesos a forma binária do número decimal 15. A representação do número decimal 15 em binário foi colocada como 1111, mas deveria ser 01111 , visto que o zero também é necessário para representação binária. Na estratégia 2, utilizando o conceito das lâmpadas o aluno conseguiu atribuir a importância devida ao número zero na representação de um número binário - como não foi feito na primeira estratégia. A primeira abstração com os alunos de frente e de costas para a turma, em partes funcionou, a abstração das lâmpadas foi mais eficiente para alguns.

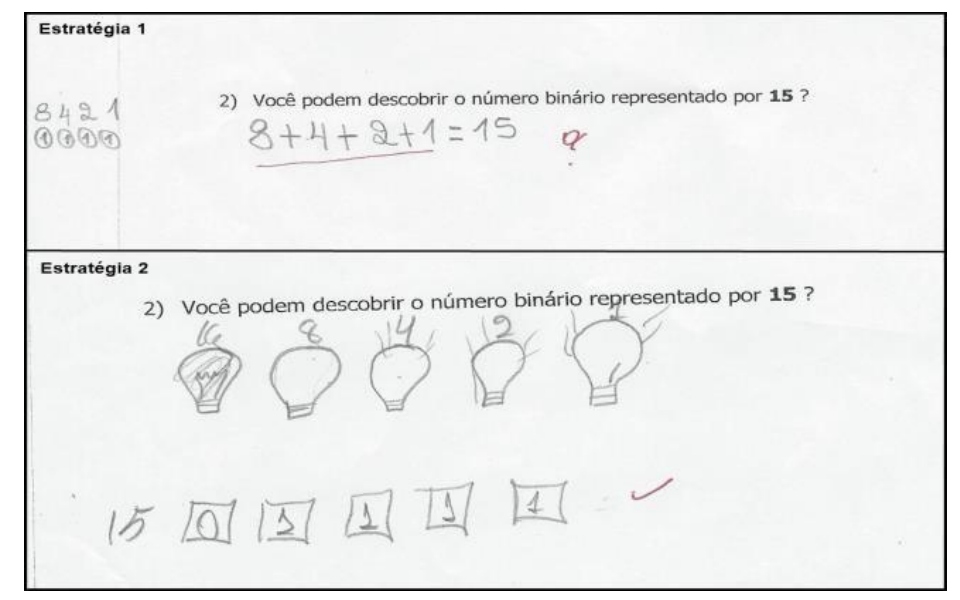

Figura 2 - Atividade de conversão de decimal para binário

Outra atividade realizada durante a gincana foi a atividade "Árvore de decisão". A árvore de decisão utilizada na atividade vai de 0 a 7 . Para explicar a atividade o monitor utilizou uma combinação de perguntas como "O número $\mathrm{X}$ é maior ou igual que o número $\mathrm{Y}$ ?" ou "O número $\mathrm{X}$ é menor que o número $\mathrm{Y}$ ?". Os alunos respondiam somente sim ou não, desta forma uma sequência era criada através das possibilidades dos zeros e dos uns até que se descobrisse a resposta. Com as explicações seguintes, o "SIM" foi relacionado ao número 1 e o "NÃO" ao 0. Então foi explicado que essa sequência de "SIM" e "NÃO" corresponderia a um número binário qualquer (sim, não, sim - 101). 


\section{- Estratégias (parte 2 - árvore de decisão)}

Na estratégia 1 o grupo enumerou cada valor de $\mathrm{X}$ com as letras do alfabeto, assim, quando fossem converter os números de decimal para binário, o entendimento seria melhor. Uma estratégia interessante.

$\mathrm{Na}$ estratégia 2 os alunos utilizaram o valor de um número decimal colocado acima de cada bit ligado para converter o valor de $\mathrm{X}$ de decimal para binário. Contudo, esqueceram que o número binário escrito com apenas três valores estava incompleto assim como foi ensinado - é necessário no mínimo cinco números, zeros e uns, para escrever um número binário. Portanto, ao invés de o valor de $\mathrm{x}=1$ ser 001 , seria na verdade 00001 como foi feito no exemplo da estratégia 1.

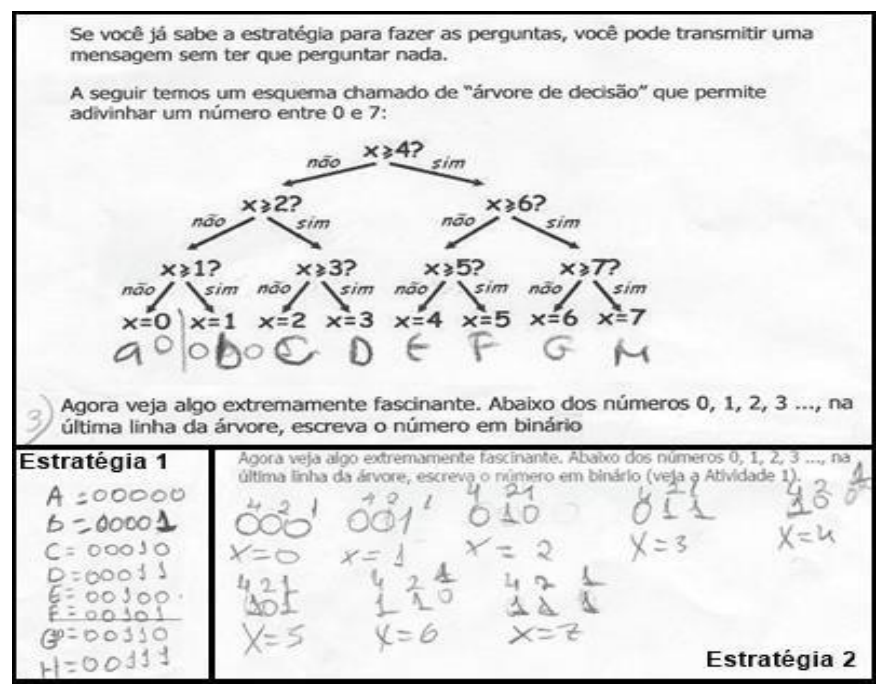

Figura 3 - Árvore de decisão, duas estratégias.

Dessa forma, os alunos só conseguiram responder corretamente a segunda questão. Na primeira questão eles confundiram e acabaram trocando o 0 (não) pelo 1 (sim). Os mesmos associaram o número um (1) ao sim e o zero (0) ao não, mas a questão não pedia isso. Na terceira questão os alunos deveriam transformar todos os números decimais da árvore de decisão em números binários, mas eles não conseguiram. Apesar de repetidas explicações, os alunos sentiram dificuldades na resolução.

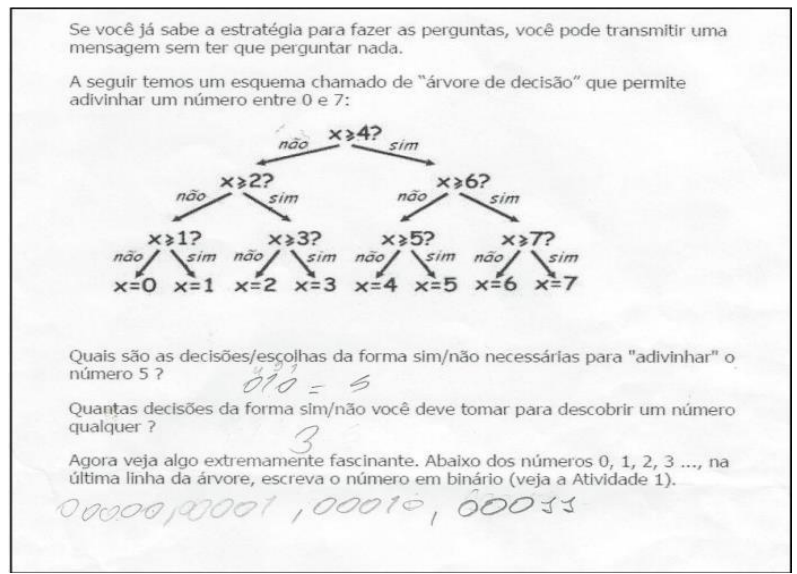

Figura 4 - Árvore de decisão, outra estratégia. 


\section{- Estratégias (parte 3-Algoritmos)}

Durante o terceiro encontro foi solicitado que os alunos elaborassem um algoritmo como atividade para fixação. Cada grupo deveria desenvolver um algoritmo para preparação de um miojo. Uma das estratégias utilizadas pelas equipes foi a enumeração das linhas do algoritmo, colocando um comando por linha. Notase que o grupo prestou atenção às explicações e conseguiu desenvolver o algoritmo com sucesso e bastante detalhado.

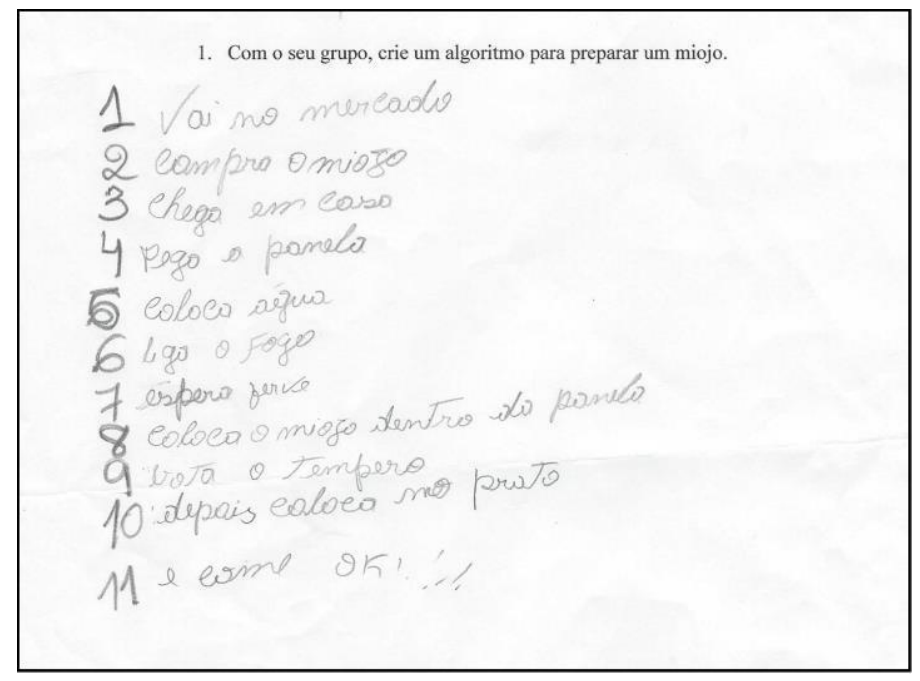

Figura 5 - Criação do algoritmo do miojo.

\section{Considerações finais e trabalhos futuros}

Este trabalho apresentou um relato de experiência do planejamento, execução, e identificação das estratégias utilizadas pelos alunos na resolução das atividades de uma gincana desplugada. Os resultados foram satisfatórios, pois o intuito da gincana foi o de ensinar conceitos computacionais, estimulando os alunos a raciocinar e desenvolver sua própria estratégia de resolução de problemas empregando os assuntos ministrados durante a gincana.

Como trabalhos futuros esperamos realizar a análise qualitativa das diferentes estratégias utilizadas pelos alunos e incluindo relatos dos próprios alunos. Também planeja-se executar uma nova gincana buscando contemplar outros conceitos computacionais.

\section{Referências}

Barros, L., Ribeiro, S.P.S., Oeiras, J. (2009) Projeto de Extensão Universitária para apoio e realização da Olimpíada Brasileira de Informática em Escolas. In: XXIX Congresso da SBC - XVII WEI, Bento Gonçalves.

Bell, T., Witten, I, H. e Fellows, M. (2011). Computer Science Unplugged: Ensinando Ciência da Computação sem o uso do computador. Tradução coordenada por Luciano Porto Barreto. 
Costa, J.; Costa, A.; Peres, S. e Teixeira, G. (2011). "Desvendando a Ecologia Local: Atividades Interativas". Revista Brasileira de Ensino de Ciência e Tecnologia, v.4, n.3.

FRANÇA, R. S.; SILVA, W. C.; AMARAL, H. J. C. Ensino de Ciência da Computação na Educação Básica: Experiências, Desafios e Possibilidades. Anais XX Workshop sobre Educação em Computação (WEI), 2012, Curitiba.

HENRIQUE, Mychelline Souto et al. Proposta para Construção de Sequências Didáticas para aulas de Matemática com uma Atividade de Computação Desplugada. In: Nuevas Ideas en Informática Educativa. 2013.

Machado, E.; Ramos, Ramos, M. e Coppola, N. (2011). "O Uso do Computador e da Internet como Ferramentas Pedagógicas". Disponível em: http://www.diaadiaeducacao.pr.gov.br/portals/pde/arquivos. Acesso em: $15 / 03 / 2013$.

Nunes, Daltro José. (2011). Ciência da Computação na Educação Básica. Disponível em <http://gestaouniversitaria.com.br/artigos/ciencia-da-computacao-na-educacaobasica--3> Acesso em: 25 de abril de 2015.

Scaico, P.; Henrique, M.; Cunha, F. e Alencar, Y. (2012). Um Relato de Experiências de Estagiários da Licenciatura em Computação com o Ensino de Computação para Crianças. Revista Renote: Novas Tecnologias na Educação, v. 10, n. 3.

Sousa, R. V.; Barreto, L. P.; Andrade, A.; Abdalla, D. (2010). "Ensinando e aprendendo conceitos sobre ciência da computação sem o uso do computador: Computação Unplugged!!!”. Práticas em Informática Na Educação: Minicursos do Congresso Brasileiro de Informática $\mathrm{Na}$ Educação, volume 1, número 1.

Tucker, A., Deek, F., Jones, J., McCowan. D., Stephenson, C., \& Verno, A. ACM K-12 Task Force (2003). A Model Curriculum for K-12 Computer Science. Final Report of the ACM K-12 Task Force Curriculum Committee.

Wing, J. M. (2008). Computational thinking and thinking about computing. Phil. Trans. R. Soc. A, 366(1881):3717-3725.

Bezerra, Fábio. Bem mais que os Bits da Computação Desplugada. $3^{\circ}$ Congresso Brasileiro de Informática na Educação (CBIE 2014). 20ª Workshop de Informática na Escola (WIE 2014).

Silva, Thiago Reis; Araújo, Glauber Galvão; Aranha, Eduardo Henrique da Silva. Oficinas Itinerantes de Scratch e Computação Desplugada para Professores como apoio ao Ensino de Computação - um Relato de Experiência. $3^{\circ}$ Congresso Brasileiro de Informática na Educação (CBIE 2014). 20ª Workshop de Informática na Escola (WIE 2014). 